\title{
A single-center report on clinical features and treatment response in patients with intestinal $\mathbf{T}$ cell non-Hodgkin's lymphomas
}

\author{
BARBARA JEZERSEK NOVAKOVIC ${ }^{1}$, SRDJAN NOVAKOVIC ${ }^{2}$ and SNEZANA FRKOVIC-GRAZIO ${ }^{3}$ \\ Departments of ${ }^{1}$ Medical Oncology, ${ }^{2}$ Tumor Biology and ${ }^{3}$ Pathology, Institute of Oncology Ljubljana, Slovenia
}

Received October 19, 2005; Accepted January 24, 2006

\begin{abstract}
Intestinal T cell lymphomas are rare, but highly aggressive in their clinical course. Generally diagnosed in advanced stages and presenting as surgical emergencies, they also respond poorly to standard anti-lymphoma therapies. Since these lymphomas are still not well characterized, we aimed our retrospective research at the evaluation of clinical features and treatment response in patients with intestinal T cell lymphomas diagnosed between February 1996 and November 2004. Fifteen patients were identified from the Department of Pathology database at the Institute of Oncology Ljubljana. Details of history, physical examination, staging investigation, treatment and outcome were taken from patient records. Ten (67\%) patients had enteropathy-associated T cell lymphoma (EATL) and $5(33 \%)$ had peripheral $\mathrm{T}$ cell lymphoma (PTCL). Surgery was performed on 11 patients with 8 cases on an emergency basis; all visible disease was resected in only 3 patients. In the continuation of treatment, all 15 patients received chemotherapy (predominantly $\mathrm{CHOP}$ ). Six patients were treated with field radiotherapy as a
\end{abstract}

Correspondence to: Dr B. Jezersek Novakovic, Department of Medical Oncology, Institute of Oncology Ljubljana, Zaloska 2, 1000 Ljubljana, Slovenia

E-mail: bjezersek@onko-i.si

Abbreviations: BFM, aggressive combination of cytotoxic drugs designed to treat patients with acute lymphoblastic leukemia and other types of highly aggressive lymphomas; CBVPP, combination of cytotoxic drugs (cyclophosphamide, carmustine, etoposide, procarbasine, steroids); CD, cluster of differentiation; CHOP, combination of cytotoxic drugs (doxorubicin, cyclophosphamide, vincristine, steroids); CHT, chemotherapy; CNS, central nervous system; COP, combination of cytotoxic drugs (cyclophosphamide, vincristine, steroids); CR, complete response; EATL, enteropathyassociated $\mathrm{T}$ cell lymphoma; NC, stable disease; PD, progressive disease; PTCL, peripheral T cell lymphoma; TIA1, T cell restricted intracellular antigen 1; VACPE, combination of cytotoxic drugs (etoposide, doxorubicin, cyclophosphamide, vincristine, steroids)

Key words: clinical features, intestinal $\mathrm{T}$ cell lymphoma, nonHodgkin's lymphoma, treatment response part of the first treatment. In total, complete response was achieved in 6 patients (40\%) with a median duration of 5.3 months (range, 2 to 12 months), stable disease in 3 patients $(20 \%)$, and progressive disease in 6 patients $(40 \%)$. Results were better in patients with limited disease. The most frequent treatment complications were small bowel perforation, obstruction, gastrointestinal bleeding, and infection. Even though some patients underwent second- and third-line treatment, $13(87 \%)$ of the total 15 patients died from progressive disease or complications of treatment. The actuarial 1 - and 5-year survival rates were $33 \%$ and $9 \%$, respectively. The prognosis and standard treatment of patients with intestinal $\mathrm{T}$ cell lymphomas are unsatisfactory with only a few long-term survivors. Therefore, earlier diagnosis and the development of more effective treatments are urgently required to improve the prospects of these patients.

\section{Introduction}

Primary gastrointestinal lymphomas account for 5-10\% of all gastrointestinal tumors and are the most common extranodal lymphomas. Only about $30 \%$ of gastrointestinal lymphomas are primarily located in the small intestine, and have different features from gastric lymphomas. More than two-thirds of intestinal lymphomas are supposed to be of B cell lineage, while $\mathrm{T}$ cell intestinal lymphomas are rather infrequent. According to the REAL classification of lymphomas, intestinal T cell lymphomas were subdivided into enteropathy-associated $\mathrm{T}$ cell lymphomas (EATL) and non-enteropathy-associated $\mathrm{T}$ cell lymphomas that are now considered peripheral $\mathrm{T}$ cellderived lymphomas by the WHO classification. Intestinal $\mathrm{T}$ cell lymphomas are, in contrast to B cell lymphomas, often multifocal and most frequently localized in the jejunum or proximal ileum (1-5).

Furthermore, intestinal $\mathrm{T}$ cell lymphomas carry a very poor prognosis because they are often diagnosed in advanced stages in patients who are unable to tolerate any kind of treatment due to their poor performance status. Patients present with weight loss, abdominal pain, diarrhea, B symptoms and frequently with features of small bowel obstruction or perforation. Emergency surgical interventions are regularly required, and further chemotherapy treatment is unsatisfactory both in terms of overall response and response duration. Moreover, a large proportion of patients are unable to finish the scheduled chemotherapy treatment, and only a select few can tolerate the scheduled radiotherapy $(1,6-9)$. 
According to the devastating prognosis of patients with intestinal $\mathrm{T}$ cell lymphomas, more effective treatment alternatives and strategies to achieve earlier diagnosis are urgently needed. Additional characteristics of the disease and prognostic factors should also be studied to extend our knowledge of this rare disease and thus improve the outcome of these patients. With this purpose, we retrospectively analyzed a series of 15 patients with $\mathrm{T}$ cell intestinal lymphoma who were admitted to the Institute of Oncology Ljubljana between February 1996 and November 2004.

\section{Patients and methods}

This retrospective study includes 15 patients with intestinal T cell lymphomas diagnosed between February 1996 and November 2004 at the Institute of Oncology Ljubljana. Patients were considered to have primary intestinal lymphoma according to the criteria of Isaacson (10). Details of presenting history, physical examination, staging investigation, treatment and outcome were taken from patient records. Of the 15 patients evaluated, 10 had EATL (67\%) and 5 had peripheral T cell lymphoma (PTCL) (33\%).

The staging procedure was performed according to the Ann Arbor classification modified by Musshoff and SchmidtVollmer (11) on the basis of history, physical examination, blood tests, chest radiography, abdominal ultrasound, small bowel biopsies (alternatively surgical staging in 11 patients), bone marrow biopsy, and abdominal (chest) computed tomography scans in some patients. All available histological material was reviewed to confirm the diagnosis.

Eleven patients were treated with surgical resection and surgery was urgent in 8 due to intestinal perforation or obstruction. All visible disease was resected in only 3 patients. All 15 patients were treated with chemotherapy either as a first-line treatment (4 patients) or after surgery (11 patients). A variety of chemotherapy regimens were applied over the course of study, with most containing anthracycline. Thirteen patients received CHOP, 1 patient chemotherapy according to BFM protocol, and 1 a combination of vincristine, bleomycin, chlorambucil and steroids. Six patients were treated with radiotherapy as a part of the first treatment following CHOP chemotherapy. Six patients received chemotherapy as a second-line treatment, 1 underwent surgery and 1 was treated with radiotherapy. One patient received third-line chemotherapy and 2 patients were treated with radiotherapy as the third-line treatment. The parameters analyzed were treatment response according to defined criteria (12), progression-free survival, survival, and treatment complications.

\section{Results}

The group of patients included in the study consisted of 3 female (20\%) and 12 male patients $(80 \%)$. The median age at presentation was 58 years (range, 43 to 73 years). Of the 15 patients evaluated, 10 had EATL $(67 \%)$ and 5 had peripheral T cell lymphoma (PTCL) (33\%). Two of the EATL patients had a known prior diagnosis of celiac disease and were on a gluten-free diet for approximately 3 months. In the remaining 8 patients with EATL, enteropathy was diagnosed at the time of lymphoma diagnosis. The celiac disease-associated
Table I. Patient characteristics and treatment response.

\begin{tabular}{|c|c|c|}
\hline & $\begin{array}{l}\text { EATL } \\
(n=10)\end{array}$ & $\begin{array}{l}\text { PTCL } \\
(n=5)\end{array}$ \\
\hline \multicolumn{3}{|l|}{ Sex } \\
\hline Female & 2 & 1 \\
\hline Male & 8 & 4 \\
\hline \multicolumn{3}{|l|}{ Age (years) } \\
\hline Median & 53 & 65 \\
\hline Range & $43-73$ & $57-71$ \\
\hline Celiac disease & $2(20 \%)$ & 0 \\
\hline \multicolumn{3}{|l|}{ Stage } \\
\hline I,II & $4(40 \%)$ & $2(40 \%)$ \\
\hline III,IV & $6(60 \%)$ & $3(60 \%)$ \\
\hline Emergency surgery & $7(70 \%)$ & $1(20 \%)$ \\
\hline $\mathrm{CHT}$ & $10(100 \%)$ & $5(100 \%)$ \\
\hline CHOP & $8(80 \%)$ & $5(100 \%)$ \\
\hline Other & $2(20 \%)$ & 0 \\
\hline CR after first treatment & $5(50 \%)$ & $1(20 \%)$ \\
\hline \multicolumn{3}{|l|}{ Duration of CR (months) } \\
\hline Median & 3 & 12 \\
\hline Range & $2-7$ & \\
\hline $\mathrm{NC}$ & $2(20 \%)$ & $1(20 \%)$ \\
\hline PD & $3(30 \%)$ & $3(60 \%)$ \\
\hline Dead & $8(80 \%)$ & $5(100 \%)$ \\
\hline Continuous CR ( 5 years) & $1(10 \%)$ & 0 \\
\hline
\end{tabular}

CHOP, combination of cytotoxic drugs (doxorubicin, cyclophosphamide, vincristine, steroids); CHT, chemotherapy; CR, complete response; EATL, enteropathy-associated T cell lymphoma; NC, stable disease; PD, progressive disease; PTCL, peripheral T cell lymphoma.

antibodies were not determined in the majority of patients. No patients with PTCL had a known prior diagnosis of celiac disease (Table I).

Immunohistochemically, in the EATL patients, tumor cells expressed CD3 in all 10 cases, CD8 in 7 and CD4 in 2 of 9 patients (staining was not performed in 1 patient). In 3 patients, a small proportion (less than $5 \%$ ) of cells expressed CD30, and a tumor sample of 1 patient was positive for CD56. The tumor cells expressed granzyme-B in 7 patients and TIA-1 in 5 patients, indicating the cytotoxic $\mathrm{T}$ cell origin of the tumors. In the PTCL group, tumor cells expressed CD3 in all 5 cases, and CD4 was detected in 2 patients. In only 1 tumor sample, less than $1 \%$ of cells expressed CD30.

In 11 of 15 patients, the diagnosis of intestinal $\mathrm{T}$ cell lymphoma was confirmed at laparotomy. All visible disease was resected in only 3 patients. In 8 patients, surgery was performed on an emergency basis: in 6 for intestinal perforation, and in 2 for features of small bowel obstruction. 
Table II. Symptoms, complications, and lymphoma location at diagnosis.

\begin{tabular}{lcc}
\hline & $\begin{array}{c}\text { EATL } \\
(\mathrm{n}=10)\end{array}$ & $\begin{array}{c}\text { PTCL } \\
(\mathrm{n}=5)\end{array}$ \\
\hline $\begin{array}{l}\text { Symptoms, complications } \\
\text { Gastrointestinal bleeding }\end{array}$ & $3(30 \%)$ & $2(40 \%)$ \\
Obstruction & $3(30 \%)$ & 0 \\
Perforation & $5(50 \%)$ & $1(20 \%)$ \\
Weight loss & $5(50 \%)$ & $1(20 \%)$ \\
Abdominal pain & $10(100 \%)$ & $2(40 \%)$ \\
Diarrhea & $7(70 \%)$ & $2(40 \%)$ \\
Fever & $5(50 \%)$ & $1(20 \%)$ \\
Lymphoma location at diagnosis & & \\
Multiple sites & $10(100 \%)$ & $5(100 \%)$ \\
Small intestine & $10(100 \%)$ & $5(100 \%)$ \\
Large intestine & $2(20 \%)$ & $1(20 \%)$ \\
Stomach & $4(40 \%)$ & $3(60 \%)$ \\
Extraintestinal & $6(60 \%)$ & $3(60 \%)$ \\
\hline
\end{tabular}

EATL, enteropathy-associated T cell lymphoma; PTCL, peripheral T cell lymphoma.

Except for 1 patient with PTCL who presented with intestinal perforation, all other emergency surgeries were performed in EATL patients. The remaining 4 patients were diagnosed with lymphoma from small bowel biopsies. At diagnosis, lymphoma was found at multiple locations in all 15 patients. In EATL patients, the primary locations were: multiple lesions of the small bowel (4 patients), multiple lesions of the small and large bowel (2 patients), multiple lesions of the small bowel together with distal parts of the stomach (4 patients). In PTCL patients, the primary locations were: multiple lesions of the small bowel (1 patient), lesions of the small and large bowel (1 patient), lesions of the small bowel (predominantly the duodenum) together with distal parts of the stomach (3 patients). According to the Ann Arbor classification, 2 patients with EATL had stage IIA disease, 2 stage IIB disease, 3 stage IVA and 3 stage IVB disease. Among the PTCL patients, 2 had stage IIA disease, while 2 had stage IVA and 1 stage IVB disease.

In the continuation of treatment, all 15 patients received chemotherapy as described in Patients and methods. A variety of chemotherapy regimens were applied in which anthracycline was used for 14 patients. Due to poor performance status, 1 patient received a combination of vincristine, bleomycin, chlorambucil and steroids. Eight patients finished their planned CHOP treatment, while chemotherapy was terminated early due to progression of the disease in 6 patients or massive bleeding and intestinal perforation after the first BFM course in 1 patient. Six patients (4 with complete response after $\mathrm{CHOP}$ and 2 with partial response after $\mathrm{CHOP}$ ) were treated with field radiotherapy as a part of the first treatment, and all achieved complete response. Two other patients that finished their CHOP treatment proceeded to second-line treatment due to an insufficient response (stable

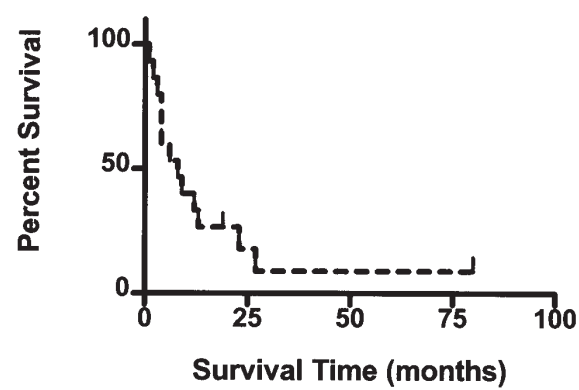

Figure 1. Kaplan-Meier survival curve of patients with intestinal T cell lymphomas. Ten patients had enteropathy-associated T cell lymphoma (EATL) and 5 patients peripheral $\mathrm{T}$ cell lymphoma (PTCL).

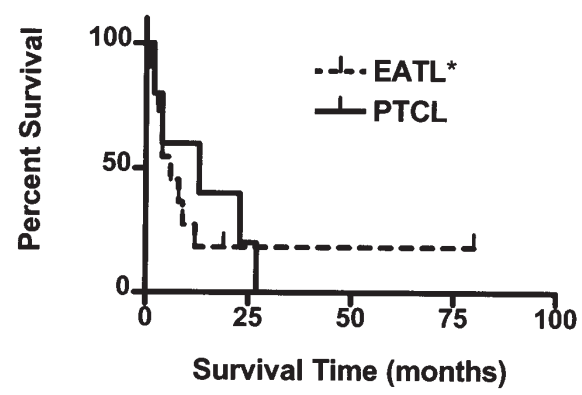

Figure 2. Survival curves according to histological types of intestinal T cell lymphomas (EATL and PTCL). *Two patients with EATL are still alive 19 and 80 months from diagnosis.

disease). In total, complete response was achieved in 6 patients (40\%) with a median duration of 5.3 months (range, 2 to 12 months), stable disease in 3 patients $(20 \%)$, and progressive disease in 6 patients $(40 \%)$. Out of 6 patients with localized disease, 5 patients $(83 \%)$ reached complete response with a median duration of 5.8 months (range, 2 to 12 months), and 1 patient $(17 \%)$ progressed. On the other hand, $5(56 \%)$ of 9 patients with advanced disease progressed, the disease was stable in 3 patients $(33 \%)$, and complete response was achieved in just 1 patient (11\%) and lasted 3 months. Details according to histological type are given in Table I.

Second-line treatment consisted of chemotherapy in 8 patients ( 1 patient CHOP, 1 patient COP, 2 patients VACPE, 1 patient CBVPP, and 1 patient with CNS relapse CBVPP with middle dose methotrexate), radiotherapy in 1 patient, and salvage surgery in 1 patient. Progression occurred in all cases except 2 patients treated with CBVPP. One of these patients entered complete remission, but experienced a CNS relapse after 3 months, and is receiving third-line treatment CBVPP with a middle dose methotrexate. The second patient treated for a CNS relapse has finished treatment with cranial irradiation and is well and alive for more than 5 years. Two other patients had third-line treatment with irradiation of the entire abdomen, but progressed either immediately or 3 months following the cessation of radiotherapy.

Treatment complications were quite frequent and occurred predominantly in EATL patients. There were perforations of the small bowel in 3 patients (some were multiple and discovered in postmortem analysis), obstruction of the small bowel in 2 patients, development of entero-enteric fistula and enterocutaneous fistula in 1 patient, abscess formation in 1 
patient, gastrointestinal bleeding in 5 patients, infectious complications (including septicemia) in 3 patients, and diarrhea in 1 patient (Table II).

Thirteen (87\%) of the total 15 patients have died (Fig. 1). The median survival duration of those who died was 6 months (range, 1 to 27 months). All deaths were from progressive disease except 1 patient who died of massive bleeding and intestinal perforation after the first BFM course (that resulted in the stagnation of lymphoma). In the group of EATL patients, 8 of 10 have died with a median survival of 5 months (range, 1 to 12 months). In the PTCL group, all 5 patients have died with a median survival of 13 months (range, 2 to 27 months). The difference between the EATL and PTCL was not significant ( $\mathrm{p}=0.69$ ) (Fig. 2). According to disease stages, the median survival duration of those who died was 9 months (range, 4 to 23 months) for localized disease, and 4 months (range, 1 to 27 months) for advanced disease. The difference was not statistically significant.

Two patients are still alive at 19 and 80 months from diagnosis, with the first being treated for a second relapse (a CNS relapse) and the second is disease-free 66 months after completion of his secondary treatment also for a CNS relapse. The actuarial 1- and 5-year survival rates are $33 \%$ and $9 \%$, respectively.

\section{Discussion}

Our study presents the clinical course of 15 patients with $\mathrm{T}$ cell intestinal lymphomas in which two-thirds of patients had EATL and one-third of patients PTCL. The distribution of histological type was similar to the one reported by Daum et al who observed $80 \%$ of EATL among 35 patients with intestinal $\mathrm{T}$ cell lymphoma (1). The median age in our group was also comparable to the median age reported by others $(1,13,14)$, but tended to be higher than in studies of Kim et al and Gale et al $(15,16)$. Patients with PTCL were older at disease presentation but the difference was not statistically significant ( $\mathrm{p}=0.09)$. Both types of $\mathrm{T}$ cell intestinal lymphomas were detected predominately in males $(80 \%)$, which was analogous to findings by Pellatt et al and Gale et al $(13,16)$, but contrary to observations by three other studies $(1,14,15)$.

Only 2 of the EATL patients had a known prior diagnosis of celiac disease and were on a gluten-free diet, while enteropathy was not diagnosed in remaining 8 patients until the lymphoma was discovered. The ratio of patients with known prior celiac disease in our research is very low compared to $66 \%$ of celiac patients in the study of Daum et al (1), but comparable to $26 \%$ and $35 \%$ of prior known celiac patients reported by two other studies $(13,16)$. The low proportion of pre-existing diagnoses of celiac disease explains why the diagnosis of lymphoma was confirmed following laparotomy in as much as $73 \%$ of our patients, and with endoscopic procedures and small bowel biopsies in the 4 remaining patients.

The presenting clinical features of lymphoma were also inconclusive with abdominal pain and diarrhea being the most common, especially in the EATL group. Weight loss and fever were observed in approximately half of patients, again more often in the EATL group. The frequency of initial complications was high with $50 \%$ of EATL patients suffering from intestinal perforation and 30\% from either obstruction or gastrointestinal bleeding. However, complications were less common in the PTCL group, except for gastrointestinal bleeding. In total, emergency surgery procedures were necessitated in 7 of 10 EATL patients and in 1 of 5 PTCL patients. Comparing these data with the two larger studies of Daum et al and Gale et al, we can find equivalent rates of initial complications and similar frequencies of predominant presenting symptoms $(1,16)$.

Similar to studies by Kim et al and Lopez-Guillermo et al $(14,15)$, our study included a larger proportion of patients with advanced disease compared to other authors $(1,13,16)$. In all of our patients, lymphoma was also found at multiple locations. However, even though all visible lymphoma masses were resected in only 3 patients, all 15 patients received chemotherapy. This was CHOP in the majority of patients, and less aggressive chemotherapy in 1 patient due to his poor performance status. In other studies, the proportion of patients treated with chemotherapy was $66 \%$ (1), $77 \%$ (16), $86 \%$ (15), $87 \%$ (13) and 96\% (14), but never $100 \%$.

Despite the aggressive approach to first-line treatment, our results were disappointing since complete remission was achieved in just $40 \%$ of patients regardless of histological type. Response was better in the EATL group (50\% complete responses) than in the PTCL group (20\% complete responses; 1 patient). All patients that achieved complete remission were treated with CHOP plus field radiotherapy, but ultimately relapsed with a short remission duration: a median of 5.3 months (range, 2 to 12 months) in total and shorter for EATL with a median of 3 months (range, 2 to 7 months), while the only patient with PTCL remained disease-free for 12 months. Gale et al achieved a response in $58 \%$ of patients (complete remission in $41 \%$ ) with a median duration of 6 months. Furthermore, $21 \%$ of patients remained in durable first remission (16). The distribution of complete responses in our study was higher in the group of patients with localized disease $(83 \%)$ versus just $11 \%$ (1 patient) in patients with advanced disease. Daum et al reports that $35 \%$ of patients with intestinal $\mathrm{T}$ cell lymphoma are in complete remission after potentially curative therapy (CHOP with or without resection), but all complete responses were achieved in patients with localized disease. None of the patients with advanced disease reached complete response or received radiotherapy, due mostly to early deaths in this group. When complete response was achieved, its median duration was much longer (median, 28 months; range, 17 to 39 months) compared to our patients, and $33 \%$ of patients were in stable durable remission (1). In the studies of Lopez-Guillermo et al and Pellatt $e t a l$, the percentages of patients reaching complete response were $27 \%$ (median duration of 20 months) and $41 \%$, respectively $(13,14)$.

The results of salvage treatment were worse with just 2 of 10 patients in complete remission. In 1 patient, this was a stable long remission lasting more than 5 years from secondary treatment, while complete response lasted only 3 months in the other patient. Salvage treatment results are comparable to two larger studies reporting very few longterm survivors $(1,16)$.

The survival of patients with $\mathrm{T}$ cell intestinal lymphoma is distressing. Domizio et al documented a 25\% 5-year survival 
in patients with intestinal T cell lymphomas (17), and a similarly poor outcome was reported by Morton et al (18), d'Amore et al (19), and Egan et al (20). In the group of peripheral $\mathrm{T}$ cell lymphomas, the intestinal $\mathrm{T}$ cell lymphoma patients had a median survival of just 4 months, while the overall median survival was 25 months (14). Pellatt et al reported the worst median survival of 0.79 years for patients with intestinal $\mathrm{T}$ cell lymphomas (13). In the study by Gale et al, $84 \%$ of patients have died with a median survival of 7.5 months, and actuarial 1- and 5-year survival rates of $38.7 \%$ and $19.7 \%$, respectively (16). Finally, Daum et al reported a $28 \%$ 2-year cumulative survival for patients with intestinal $\mathrm{T}$ cell lymphoma, with the survival rates almost equal between EATL (28\%) and non-EATL patients (29\%). The survival of patients with limited disease $(38 \%)$ was better than in patients with advanced disease $(14 \%)$, but the difference was not significant (1). In our study, $87 \%$ of patients have died with a group median survival of 6 months. All deaths were from progressive disease except 1 patient who died of bleeding and perforation after the first chemotherapy cycle. Of the EATL patients, $80 \%$ have died with a median survival of 5 months, while all PTCL patients have died with a median survival of 13 months. According to disease stage, the median survival was 9 months for localized disease, and 4 months for advanced disease. The actuarial 1- and 5-year survival rates were $33 \%$ and $9 \%$, respectively.

Taken together, the prognosis of patients with intestinal $\mathrm{T}$ cell lymphoma has not improved over the last decade and remains dismal. Standard treatment with CHOP seems to confer a survival benefit to patients with localized disease, although the overall survival continues to be unsatisfactory. More aggressive variants of chemotherapy predominantly result in pronounced toxicity without improved treatment outcomes. Thus, earlier diagnosis and the development of more effective treatments are required to change the prospect of these patients. Biological therapy (e.g. with alemtuzumab) could possibly affect the miserable prognosis of patients with intestinal T cell lymphomas (8).

\section{References}

1. Daum S, Ullrich R, Heise W, Dederke B, Foss HD, Stein H, Thiel E, Zeitz M and Riecken EO: Intestinal non-Hodgkin's lymphoma: A multicenter prospective clinical study from the German Study Group on Intestinal non-Hodgkin's Lymphoma. J Clin Oncol 21: 2740-2746, 2003.

2. Radaszkiewicz T, Dragosics B and Bauer P: Gastrointestinal malignant lymphomas of the mucosa-associated lymphoid tissue: factors relevant to prognosis. Gastroenterology 102: 1628-1638, 1992.

3. Harris NL, Jaffe ES, Stein H, Banks PM, Chan JK, Cleary ML, Delsol G, De Wolf-Peeters C, Falini B and Gatter KC: A revised European-American Classification of lymphoid neoplasms: a proposal from the International Lymphoma Study Group. Blood 84: 1361-1392, 1994.

4. Harris NL, Jaffe ES, Diebold J, Flandrin G, Muller-Hermelink HK, Vardiman J, Lister TA and Bloomfield CD: World Health Organization classification of neoplastic diseases of the hematopoietic and lymphoid tissues: Report of the Clinical Advisory Committee Meeting, Arlie House, Virginia, November 1997. J Clin Oncol 17: 3835-3849, 1999.
5. Isaacson P, Wright D, Ralfkiaer E and Jaffe ES: Enteropathytype T-cell lymphoma. In: World Health Organization Classification of Tumors: Pathology and Genetics: Tumours of Haematopoietic and Lymphoid Tissue. Jaffe ES, Harris NL, Stein H and Vardiman JW (eds). IARC Press, Lyon, pp208-209, 2001.

6. Kataoka I, Arima F, Nishimoto J, Watanabe T, Kobayashi Y, Tamura R, Yamamoto S, Matsuno Y, Shimoda T and Tobinai K: Enteropathy type T-cell lymphoma showing repeated small bowel rupture and refractoriness to chemotherapy; a case report. Jpn J Clin Oncol 32: 546-549, 2002.

7. Crump M, Gospodarowicz M and Shepherd FA: Lymphoma of the gastrointestinal tract. Semin Oncol 26: 324-337, 1999.

8. Woehrer S, Chott A, Drach J, Puespoek A, Hejna M, Hoffmann M and Raderer M: Chemotherapy with cyclophosphamide, doxorubicin, etoposide, vincristine and prednisone (CHOEP) is not effective in patients with enteropathy-type intestinal T-cell lymphoma. Ann Oncol 15: 1680-1683, 2004.

9. Ruskone-Fourmestraux A and Rambaud JC: Gastrointestinal lymphoma: prevention and treatment of early lesions. Best Practice Res Clin Gastroenterol 15: 337-354, 2001.

10. Isaacson P: Gastrointestinal lymphoma. Hum Pathol 25: 1020-1029, 1994.

11. Musshoff K and Schmidt-Vollmer H: Prognosis of non-Hodgkin's lymphoma with special emphasis on the staging classification. Z Krebsforsch 83: 323-341,1975.

12. Zinzani PL, Magagnoli M, Pagliani G, Bendandi M, Gherlinzoni F, Merla E, Salvucci M and Tura S: Primary intestinal lymphoma: Clinical and therapeutic features of 32 patients. Haematologica 82: 305-308, 1997.

13. Pellatt J, Sweetenham J, Pickering RM, Brown L and Wilkins B: A single-centre study of treatment outcomes and survival in 120 patients with peripheral T-cell non-Hodgkin's lymphoma. Ann Hematol 81: 267-272, 2002.

14. Lopez-Guillermo A, Cid J, Salar A, Lopez A, Montalban C, Castrillo JM, Gonzalez M, Ribera JM, Brunet S, Garcia-Conde J, Fernandez de Sevilla A, Bosch F and Montserrat E: Peripheral T-cell lymphomas: initial features, natural history, and prognostic factors in a series of 174 patients diagnosed according to the REAL classification. Ann Oncol 9: 849-855, 1998.

15. Kim K, Kim WS, Jung CW, Im YH, Kang WK, Lee MH, Park CH, Ko YH, Ree HJ and Park K: Clinical features of peripheral T-cell lymphomas in 78 patients diagnosed according to the Revised European-American Lymphoma (REAL) classification. Eur J Cancer 38: 75-81, 2002.

16. Gale J, Simmonds PD, Mead GM, Sweetenham JW and Wright DH: Enteropathy-type intestinal T-cell lymphoma: Clinical features and treatment of 31 patients in a single center. J Clin Oncol 18: 795-803, 2000.

17. Domizio P, Owen RA, Shepherd NA, Talbot IC and Norton AJ: Primary lymphoma of the small intestine: A clinicopathological study of 119 cases. Am J Surg Pathol 17: 429-442, 1993.

18. Morton JE, Leyland MJ, Vaughan Hudson G, Vaughan Hudson B, Anderson L, Bennett MH and MacLennan KA: Primary gastrointestinal non-Hodgkin's lymphoma: a review of 175 British National Lymphoma Investigation cases. Br J Cancer 67: 776-782, 1993.

19. d'Amore F, Brincker H, Gronbaek K, Thorling K, Pedersen M, Jensen MK, Andersen E, Pedersen NT and Mortensen LS: NonHodgkin's lymphoma of the gastrointestinal tract: a populationbased analysis of incidence, geographic distribution, clinicopathologic presentation features, and prognosis. J Clin Oncol 12: 1673-1684, 1994.

20. Egan LJ, Walsh SV, Stevens FM, Connolly CE, Egan EL and McCarthy CF: Celiac-associated lymphoma. A single institution experience of 30 cases in the combination chemotherapy era. J Clin Gastroenterol 21: 123-129, 1995. 